\title{
sciendo TECHNICAL EXPERIMENTAL EQUIPMENT FOR MAKING POROUS WIRE SAMPLES
}

DOI 10.2478/ntpe-2018-0084

\author{
Dr. Andrzej Jakubowski \\ Maritime University of Szczecin, Poland \\ Dr. Stanislau Dounar \\ Belarusian National Technical University, Belarus
}

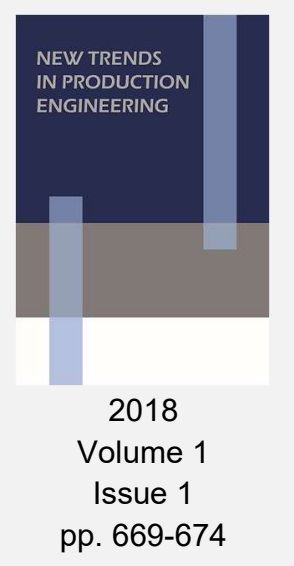

\begin{abstract}
Original experimental technical equipment for making samples in the form of permeable tubes of porous material, i.e. coiled wire. The article describes the construction of the equipment, the processes of forming and pressing the wire semi-product and methods of fixing the ends of the wire product.
\end{abstract}

Keywords: wire, mandrel, winding, radial reduction, fixing of the ends

\section{INTRODUCTION}

Of numerous products made of porous permeable materials used in technology (Belov, 1987; Vityaz et al., 1987; Sinelnikov et al., 1983), coiled wire porous material (CWPM) has not been fully examined (Petyushik and Yakubouski, 2000). Products that can be made of this material include permeable tubes, elements of filtering systems, silencers, heat pipes etc. The use of CWPM, characterized by an organized and controllable structure of pores, not only enables effective management of processes such as fluid filtration, sound absorption, temperature control, but also allows us to improve these processes. It is necessary for experimental testing of internal construction and useful properties of CWPMs to have appropriate technological equipment for producing samples of these materials.

\section{FORMATION OF A WIRE SEMI-PRODUCT}

Winding is a process used in a wide range of technical fields. The necessary elements of the process include a filament, mandrel, filament guide and mechanisms for mandrel rotary motion, reciprocating motion of the filament guide and filament tensioner (Sukharev and Matyushev, 1982). Filament is a generic name of a slender and flexible material of any nature often subjected to winding. There are monofilaments and poly-filaments, in which a filament is an elementary fibre in strands making a more complex structure. The mandrel is understood as an object on which a filament is wound. It can have a form of a roll, tube, spool, frame etc. Winding is executed by sequence wrapping of the mandrel with successive turns of tight filament, providing a layered distribution of turns on the product surface.

The process of filament winding results in a system, whose mechanical properties allow it to be considered as an object called the product of winding, or packing. Depending on the intended application and required properties, the packing can be made in a variety of shapes (Figure 1,a-e), by using an appropriate mandrel and specific method of winding (Matyushev, 1979). The desired shape of the packing is obtained by changing basic parameters of the process of winding (length of distribution $L$, co-ordinate of the centre point of distribution $L_{m}$, the speed of winding) (Fig. 1,f). A structure created by adopting specific parameters of winding and selected cross-section of filament is characterized by the porous space and durability.

The case considered here is a semi-product in the form of coiled wire porous material (CWPM), a cylindrical packing with straight ends (Fig. 1,b), formed by continuous metal filament with a round cross-section (further called a wire) wound on a cylindrical mandrel (spindle). The shaping of porous space and control of WB structure takes place at the stage of wire winding. 


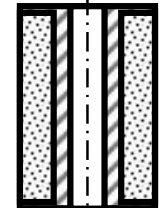

a)

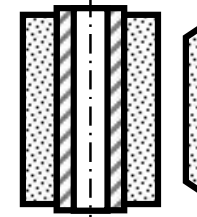

b)

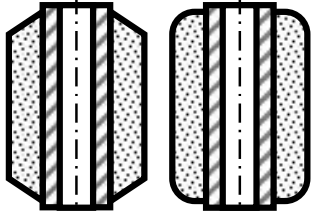

c)

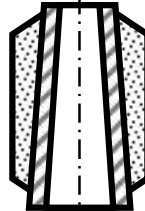

e)

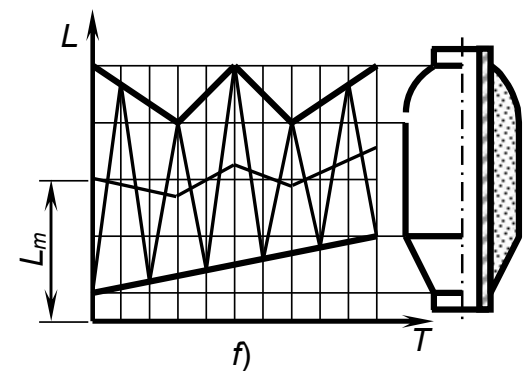

Fig. 1. The shapes of packings:

a) cylindrical, on a two-flange spool; b) cylindrical with straight ends on a reel;

c) cylindrical with conical ends on a reel; $d$ ) cylindrical with ends rounded on a reel; e) packing on a conical roll; $f$ ) mixed winding by simultaneous changing of wire turn distribution and the coordinate of the central point of distribution, and a proper shape of the packing

In order to produce wire packing and test its structural characteristics an original wire winding device (Figure 2a,b) was designed and made. The device consists of two independent mechanisms for a rotary movement of the mandrel and reciprocating motion of the filament guide. The mechanism of the rotary mandrel movement is equipped with an asynchronous AC motor 1 , worm gear 2 , three-stage belt transmission, rotary centre 4 with an end-carrier 5 , fixing flanges 6 , stationary thrust centre 7 , tensioner 8 of belt transmission 3 . The mechanism of the filament-driver reciprocating motion features a DC motor 9 , gear transmission 10 , feed screw 11 , filament guide shaft 12 , filament guide 13 , filament guide movement stoppers 14 . In addition, the device features a holder 15 with rotating seats for setting a bobbin 16 with wire 17 that is wound on a mandrel 18, and control block 19 with the buttons 20 "start" and "stop" and motor (9) speed governor 21.

The cylindrical mandrel 18 is placed between the fixing flanges 6 in the centres 4 and 7 . The spool 16 with wire 17 is set in the seats of holder 15 . The free end of the wire 17 is run through the hole of guide 13 and attached to the mandrel 18. Winding of the wire commences with the start-up of motors 1 and 9, activated by pushing the "start" button 20 on the control block 19. Once the motor 1 activates the centre 4 with the end-carrier 5 through the worm gear 2 and belt transmission 3 , the flange 6 and mandrel 18 start rotating, which leads to the winding of wire 17 attached to the mandrel. The motor 9 , in turn, through the gear transmission 10, turning the feed screw 11 causes the reciprocating motion of the guide 13 that slides along the guide shaft 12 and along the mandrel18 axis and distributes wire 17 turns through the length of mandrel 18 . The guide 13 track has a distance limited by the stoppers 14 . When the guide touches one of them, it starts moving back. In this way the turns of the wire 17 are cross wound, where the basic technological parameter is the winding angle depending on the relation between the rotary speed of mandrel 18 and the advance speed of the guide 13 . The required winding angle is set by changing the advance speed of the guide 13 (rotary speed of motor 9 ) by means of the governor 21 in the control block 19. To change the rotary speed of the mandrel 18 the belt transmission 3 stages is changed in the stop mode. After a specified number of layers is wound, motors 1 and 9 are switched off by pushing the "stop" button 20 , pushing away the thrust centre 7 and taking off the mandrel 18 with the wound wire 17 from the flanges 6 (Fig. 2,c).

The wire winding device has the following technological characteristics: the power of the AC and DC motors is, respectively, $180 \mathrm{~W}$ and $60 \mathrm{~W}$; the rotary speed of the motors, accordingly, $1350 \mathrm{rpm}$ and $3000 \mathrm{rpm}$; rotary speed of the centre for stages I, II and III is, respectively, 21 $\mathrm{rpm}, 42 \mathrm{rpm}$ and $63 \mathrm{rpm}$; advance speed of filament displacement $-0.15 \ldots 1.50 \mathrm{~m} / \mathrm{min}$; maximum possible diameter of the packing is $100 \mathrm{~mm}$; maximum packing length is also 100 $\mathrm{mm}$. The respective ranges of winding angles for stages I, II and III of the belt transmission are $2 \ldots 20^{\circ}, 3 \ldots 30^{\circ}, 5 \ldots 50^{\circ}$. 


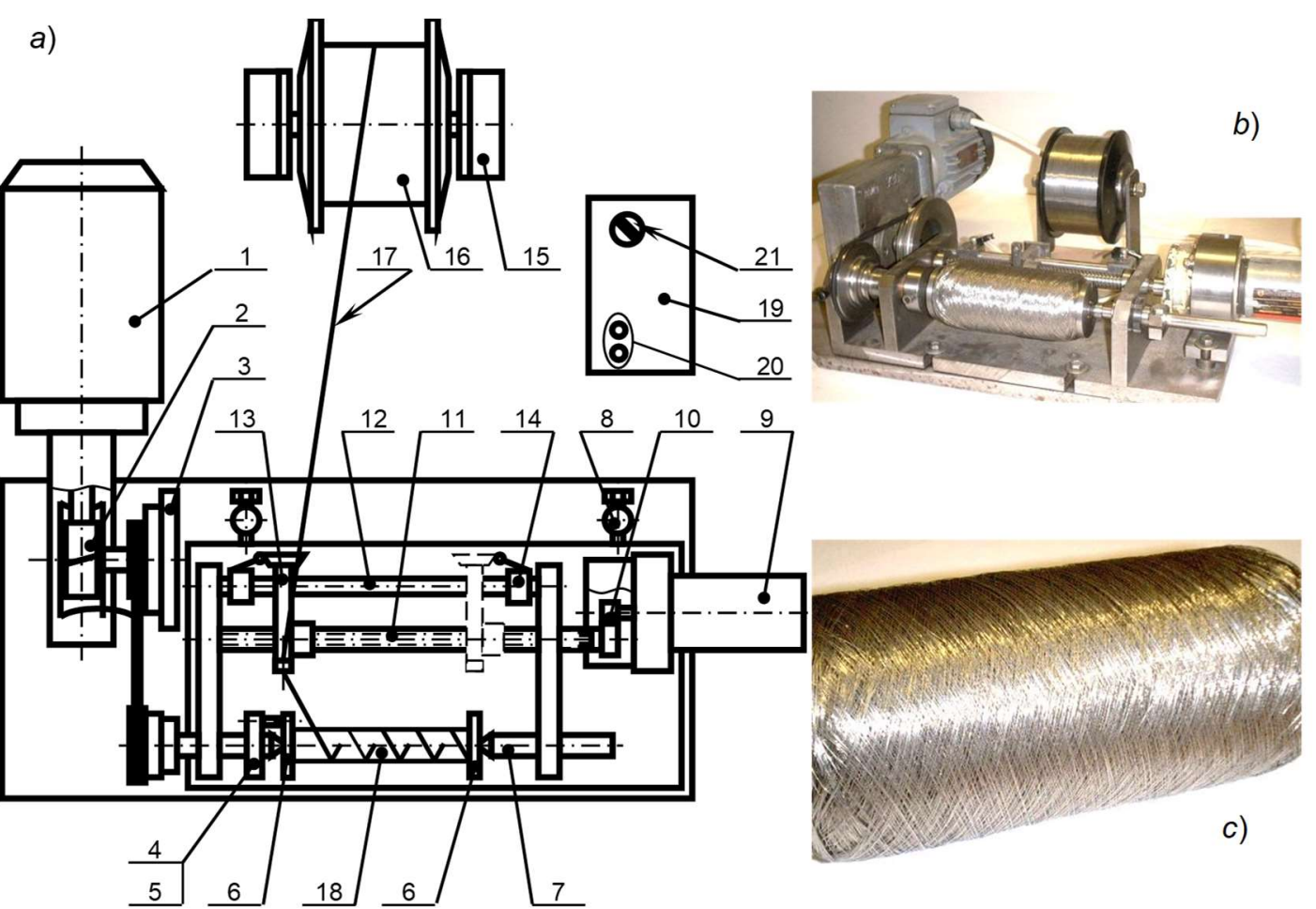

Fig. 2. The diagram of the wire winding device (a), view of the device (b) a packing (c)

\section{RADIAL REDUCTION OF THE SEM-IPRODUCT}

The final structure of the CWPM is created at the stage of plastic treatment of the packing (Komori and Itoh, 1991; Komori et al., 1992) called radial reduction. To execute radial reduction an original device for isostatic radial pressing of sealed materials was designed and made (Figure 3,a,b) (Boginskiy et al., 1992; Reut et al., 1998). The device consists of the following structural components: the body 1 on assembly rails 2, flexible insert 3 (e.g. polyurethane), two flanges 4 and 5 , lock 6 in the form of a plug with thrust thread, push rod 7 rigidly connected through a link 8 with a pull rod 9 mounted in guiding supports 10 . The bored hollow spaces inside the body 1 and inserts 3 outside make up the interior space which is filled with working fluid (e.g.industrial oil). The central opening of the insert 3 constitutes a working chamber 12 where a mould 13 is placed. The device is constructed in a manner that excludes axial deformations of insert 3 and mould 13 during the pressing. A hydraulically controlled pump provides high pressure for the process. The mould 13 for pressing of sealed materials (Fig. 3,c) consists of the following parts: rod 14, flexible polyurethane housing 15, cap 16 and lock-nut 17.

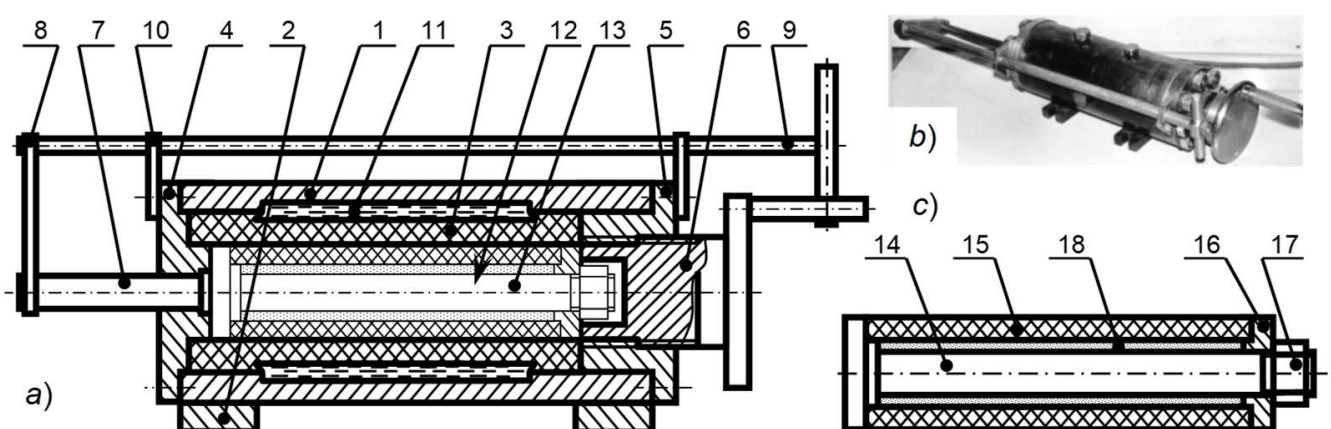

Fig. 3. The diagram of a device for radial reduction of sealed materials (a), image of the device (b) and the diagram of the mould for pressing $(c)$

During the preparation of the mould (Figure 4,a) to the pressing, on the rod 14 with the wound wire 18 (Fig. 4,b) the housing 15 is applied, closed with the cap 16 and locked by the nut 17. The assembled mould 13 (Fig. 4,C) is placed in the working chamber 12 of the device (Fig. 3,a) 
and closed by the lock 6 . The dimensions of the mould are determined by the size of working chamber 12. Then, by switching on the hydraulic pump the high-pressure working fluid is delivered to the internal space 11 of the device. Thanks to the insert 3 made of polyurethane the pressure is transferred without loss to the external side surface of mould 13 (Petyushik et al., 2003). Besides, the mould housing 15 made of polyurethane (Fig. 3,c) used as the pressing tool causes the radial load to act uniformly on the wire packing 18 placed on the rod 14 along its entire length. Once the required pressure is reached, the pump is switched off and the pressure drops in the device. In the next step, the lock 6 is opened (Fig. 3,a) and the mould is removed from the chamber 12 by means of pull rod 9 and push rod 7 . Once the mould is dismantled, the crimped product is taken out.

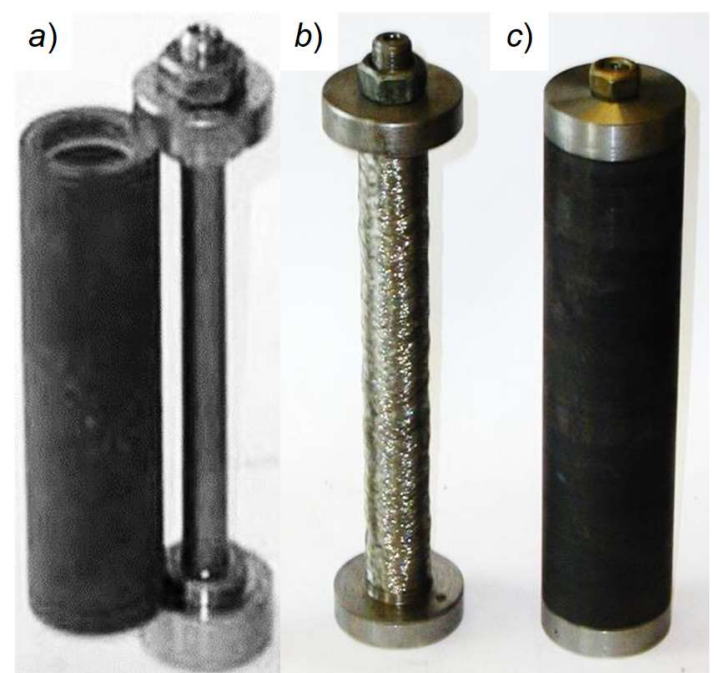

Fig. 4. View of the mould (a), packing (b) and the assembled mould (c)

The device has the following technological parameters: maximum pressure $-150 \mathrm{MPa}$, working chamber diameter and length, respectively - $28 \mathrm{~mm}$ and $140 \mathrm{~mm}$; maximum diameter and length of the product $-18 \mathrm{~mm}$ and $110 \mathrm{~mm}$.

\section{FIXING OF THE PACKING ENDS}

The pressing of wire semiproducts does not usually provide permanent fixing of wire turns at their ends, particularly when elastic or rigid wire is used (Figure 5,a). In addition, the lack of sintering operation, traditionally performed in metallurgic processes involving powder and fibrous products, gives no possibility to render extra strength to the product (Balshin, 1972; Liu et al., 2008; Duan et al., 2018). Therefore, the problem how to prevent damage to the packing ends, specifically unwinding of wire turns, can be solved by strengthening the turns at both ends, for example by using connecting tips. Depending on the conditions of product use, the following methods of fixing the ends can be used:

- rolling (Fig. 5,b) - this method is used when the tip is made of soft metal (e.g. aluminium); the tip is slid over the packing end, then by local pressing it is crimped from the outside;

- forcing in (Fig. 5,c) - this method is used right after the wire is wound on the mandrel, before the mould for pressing is assembled; thin washers made of soft metal, e.g. copper, are put on the two ends of the packing; after radial pressing these washers crimp the product ends;

- mechanical method (Fig. 5,d) - in which a tip made of any material is placed on the end and externally fastened by e.g. a stirrup;

- pouring (Fig. 5,e) - the product end is placed in a casting mould, which is then filled with molten metal or polymer, that solidifies and forms a tip of the desired shape.

The fixing of the ends by pouring can be of three types: rings, caps or reinforced by, e.g. a connector. The only restriction is the temperature that should not exceed the melting point of the most fusible material of the product. The use of metals (e.g. aluminium alloys) is justified 
when products are intended for use in high temperatures, or when it is necessary to ensure their rigid or accurate fixing.

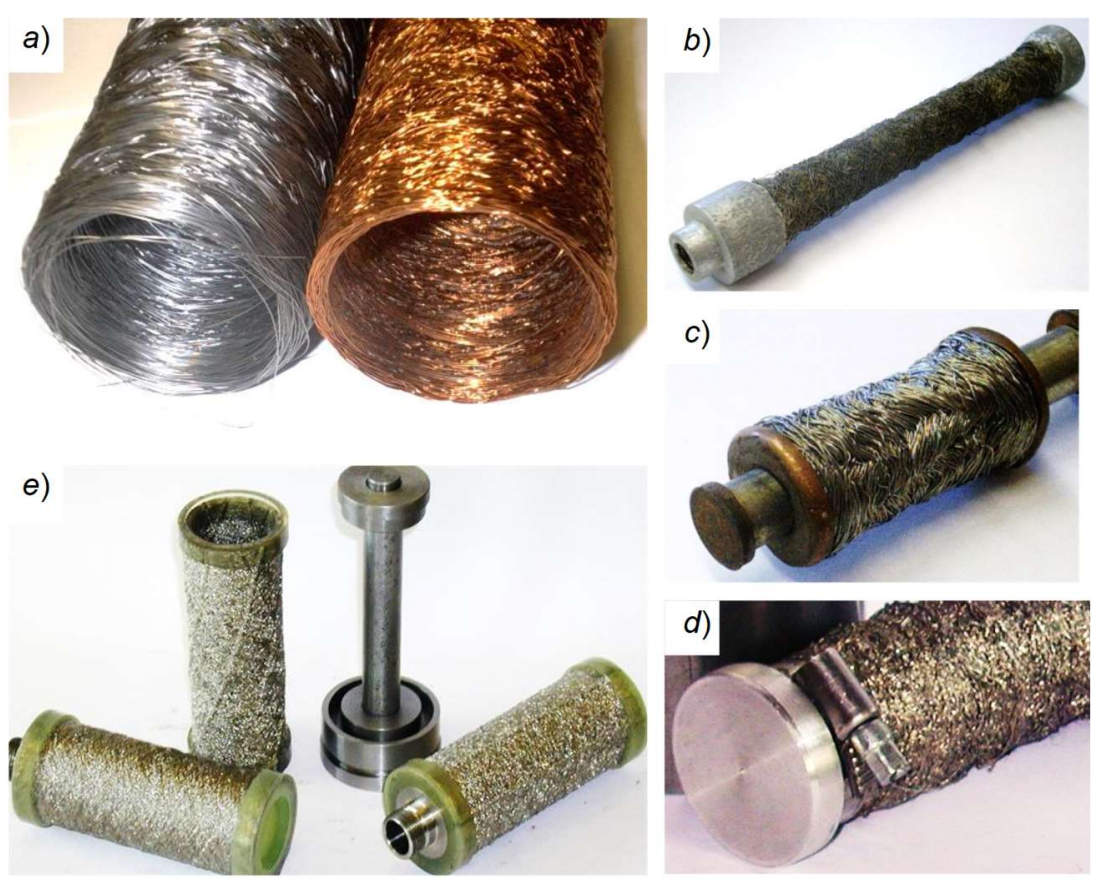

Fig. 5. View of the pressed wire tube ends (a) and methods of their fixing (b-e)

The use of polymers (e.g. polyurethane), is possible for products made of almost any type of material, including textile or polymer filaments, which are intended for use in low temperature conditions or the corrosive environment. Furthermore, the ends fixed by polymer filling may act as sealings during the installation of the product.

For example, polyurethane filling is made in a vulcanizer at a temperature of $110^{\circ} \mathrm{C}$. The product ends are first degreased, and if necessary to ensure better adhesion, covered with a special adhesive. The type of polyurethane is usually chosen for its permissible hardness. The time of polymerisation of hard types of polyurethane with Shore hardness of $\sim 95$ units (Adipren L-167, Metex-295) ranges from 60 to 90 minutes. The polymerization of polyurethanes with Shore hardness $\sim 60$ units (for obtaining high flexibility connecting surfaces) takes much more time.

If high accuracy of the dimensions of the contact or assembly surfaces is required, the packing ends made by any of the presented methods may be subjected to precision machining.

\section{CONCLUSIONS}

An original device was designed and manufactured for winding the wire onto a cylindrical mandrel and subsequent radial reduction of the wire semi-product. It is possible to make experimental samples in the form of permeable tubes from porous coiled wire porous material. To immobilize wire turns at the tube ends it is necessary to fix the ends by one of the proposed methods. The samples are used for conducting experimental tests of the internal structure and functional characteristics of wire porous material.

\section{REFERENCES}

Balshin, M.Yu. (1972). Nauchnyye Osnovy Poroshkovoy Metallurgii i Metallurgii Volokna. Moskva: Metallurgiya, 335.

Belov, S.V. (1987). Poristyye Pronitsayemyye Materialy. Moskva: Metallurgia, 335.

Boginskiy, L.S., Pechkur, V.V., Yakubouski, A.Ch. (1992). Ustroystvo dlya Pressovaniya Poroshkovykh Filtruyushchikh Elementov na Osnove Metallov, Keramiki i Polimerov. Tollyatti: TPI, pp. 17. 
Duan, L., Zhou, Zh., Yao, B. (2018). Fabrication, Structural Characterization and Uniaxial Tensile Properties of Novel Sintered Multi-Layer Wire Mesh Porous Plates. Materials, 11(1), pp.156.

Komori, T., Itoh, M. (1991). Theory of the General Deformation of Fiber Assemblies. Textile Research Journal, 61(10), pp. 588-594.

Komori, T., Itoh, M., Takaku, A. (1992). A Model Analysis of the Compressibility of Fiber Assemblies. Textile Research Journal, 62(10), pp. 567-574.

Liu, P., He, G., Wu, L. (2008). Fabrication Of Sintered Steel Wire Mesh and its Compressive Properties. Materials Science and Engineering a-Structural Materials Properties Microstructure and Processing, 489(1-2), pp. 21-28.

Matyushev, I.I. (1979). Formy Pakovok i Zakony Raskladki Niti na Krutilno-Vytyazhnykh Mashinakh dlya Khimvolokon. Khimicheskiye volokna, 4, pp. 44-45.

Petyushik, Ye.Ye., Reut, O.P., Makarchuk, D.V. (2003). Osnovy Vybora Materiala Elastichnogo Deformiruyushchego Instrumenta. Novopolotsk (Belarus): PGU, pp. 135137.

Petyushik, Ye.Ye., Yakubouski, A.Ch. (2000). Poristyye Materialy na Osnove Provoloki. Minsk: BGPA, V.5, pp. 181.

Reut, O.P., Boginskiy, L.S., Petyushik, Ye.Ye. (1998). Sukhoye Izostaticheskoye Pressovaniye Uplotnyayemykh Materialov. Minsk: Debor, 258.

Sinelnikov, Yu.l. et al. (1983). Poristyye Setchatyye Materialy. Moskva: Metallurgiya, 63.

Sukharev, V.A., Matyushev, I.I. (1982). Raschet Tel Namotki. Moskva: Mashinostroyeniye, 136.

Vityaz, P.A., Kaptsevich, V.M., Sheleg, V.K. (1987). Poristyye Poroshkovyye Materialy i Izdeliya iz Nikh. Minsk: Vysshaya shkola, 164. 